\title{
The Use of Facebook to Supplement Classroom Teaching
}

\author{
Mun Onn Lai \\ Taylor's University, Malaysia
}

\begin{abstract}
Whilst there are many articles online on the use of Facebook in education, there is a lack of research conducted on this at the University level and in particular, why students find such use to be beneficial to them. This paper explores how Facebook can be used effectively to supplement teaching and how students respond to it. Case studies were conducted using Facebook as a tool in teaching, pastoral care and in administration of the course with first year undergraduates in a Law School at a private University and these were followed-up with surveys. The research revealed some resistance to such use of Facebook as a small minority felt that education should not intrude into social networking sites. However, an overwhelming majority of the students found the use of Facebook very helpful as they already had a Facebook account and were familiar with the use of Facebook.
\end{abstract}

\section{Introduction}

A social networking site is a web-based service that allows individuals to among other things construct a public or semi-public profile within a bounded system, articulate a list of other users to share a connection and view and traverse the list of connections and those made by others within the system [1].

Facebook is a very popular social networking site. According to their website, as of October 2012, they have 1 billion monthly active users. There are 552 million daily active users on average in June 2012 [5]. In some Universities, it will be a big surprise if a student does not own a Facebook account. Some students are logged in on Facebook each time they are online. With mobile devices, some students could be on Facebook throughout the day, around the clock. While Facebook may be meant for people to keep in touch with friends and to find new ones, it is submitted that it can also be used as an educational tool.

This author has been able to find material online regarding Facebook being used in education. However, these articles mainly share about how it can be done and they usually refer to Facebook used in schools rather than in Universities. There do not seem to be much research carried out on Facebook used specifically as an education tool.

In 2008, the University of Minnesota did a study on the educational benefits of Social networking Sites [9]. This study however involved school going students.

In 2009, across the Atlantic, the University of Leicester carried out a research on how Facebook can be used to help new students settle into university social and academic life [6]. But the use of Facebook here is before registration to help students settle down in the University to minimize the chance of them withdrawing and not so much on using Facebook as an education tool.

Recently in 2011, a study by researchers in China and Hong Kong showed that Facebook can improve educational outcomes [8]. The study however focuses more on how students can connect with the faculty and other students on Facebook to discuss and share about their studies.

There appears to this author a need for a research to be conducted on the actual use of Facebook as a tool in the teaching process of students in the tertiary level, specifically in social science subjects.

This author in his interaction with his students realized the potential of Facebook as an education tool when he started interacting with them on Facebook as a means make announcements and communicate with his students. This author decided to take it to another level and use Facebook as part of the teaching process. After all, if students are already using Facebook actively, educators should then go to where the students are and try to use Facebook as a teaching tool.

In this paper, this author will be sharing his experiences in using Facebook as an educational tool for his classes, specifically in the area of teaching, pastoral care and administration. The students consist of $1^{\text {st }}$ year undergraduate students in a Law School. There are 34 students in the class and their views on the use of Facebook by this author will be shared in this paper.

Further, this author will also share the views of other lecturers in the said Law School regarding the use of Facebook. This is also important because in order for Facebook to be used to supplement the 
classroom teaching, both students and lecturers have to be open the idea.

It is submitted that while this project was carried out in a social science class, it should be relevant to other areas of studies with or without any modifications.

The purpose of this research is to see if Facebook can be used as a tool to supplement the classroom teaching of students at the tertiary level as well as assisting them to cope with the demands of University life. If it can be used in such a way, it is hoped that through this paper, educators can be encouraged to use Facebook and have some ideas of how it can be done.

\section{Preliminary Survey}

The research was started with a survey to gauge the possibility of using Facebook. 28 students took part in the initial survey and here are the results:-

- $100 \%$ indicated they have a Facebook account and they have been on Facebook for at least 2 years;

- $71 \%$ indicated they found Facebook easy to use. No one found any difficulty using Facebook;

- $61 \%$ of them said that they are on Facebook every time they go online (See Table 1 below).

Table 1. Frequency of using Facebook

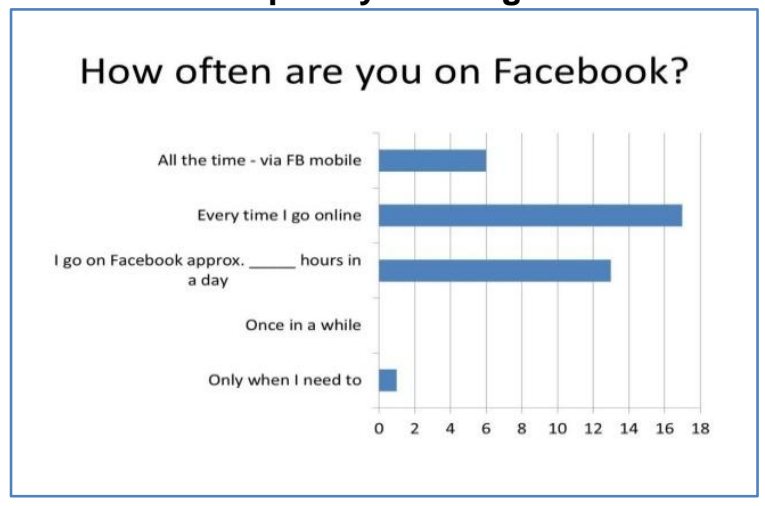

$21 \%$ said that they are on Facebook all the time via their mobile devices. $39 \%$ are on Facebook approximately 5 hours a day.

The use of Facebook by students was compared with the use of Blackboard, the Learning Management System used in our course. 57\% of them indicated they $\log$-in to Blackboard twice a week. Only $29 \%$ of them log-in to Blackboard once a day. A couple of students even indicated they have never logged-in to Blackboard before.

Finally, in response to the question "Do you think Facebook can be used as an education tool?", $64 \%$ said yes (see Table 2 below). A couple of students said no. Other comments include Facebook can be used but in a supplementary manner.
Table 2. Using Facebook in Education

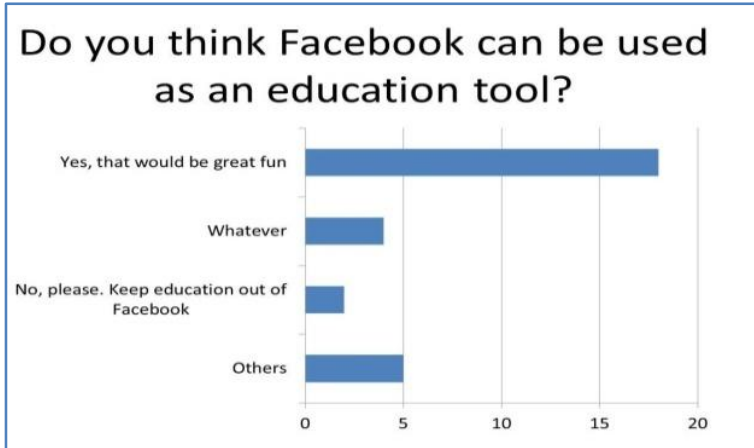

From the results of this survey, the students are ready to take part in this study as all of them have a Facebook account and none of them face any difficulties in using Facebook. A big majority are also open to the idea of using Facebook as an educational tool.

\section{Methodology}

This author adopted a mix of case studies and the use of surveys in this research. This author used Facebook in the following ways:-

- $\quad$ Teaching and giving feedback;

- Pastoral care;

- Administrative matters.

The students are required to give their feedback by taking part in survey. The surveys are drafted in such a way that requires the students to answer some close-ended questions. They are also given the opportunity to give further views in the survey. All this will be elaborated below.

\subsection{Teaching \& feedback}

Facebook was used to supplement the teaching in the following ways:-

3.1.1 Discussion forums. Discussion forums are easily set-up on Facebook by creating a "Group" (hereinafter referred to as "a FB Group").

Creating a FB Group is easy. At the "News Feed" page, one will be able to see the "Create Group..." button in the left side panel (see Figure 1 below).

Once the button is clicked, the group can be created by giving it a name and choosing the members of that group. One will also be able to choose the privacy setting. This author normally sets the group to be a "Secret Group". This means that no one outside of the group can view the discussion and students know that their privacy is respected.

This author has set up Discussion Forums to discuss reported decisions of Court cases. The 
students are required to read the decision by the judge(s) and then participate in the forum.

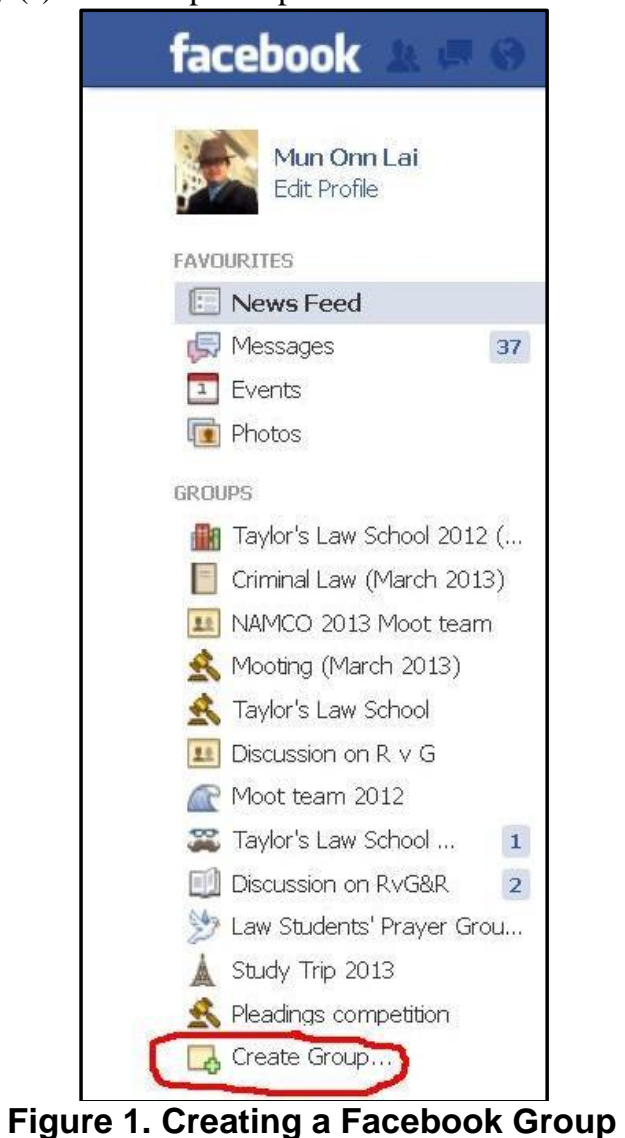

Questions will be posted and students are invited to participate in the "discussion" by stating their views and/or giving their answers by posting a comment to the question. (see Figure 2 below).

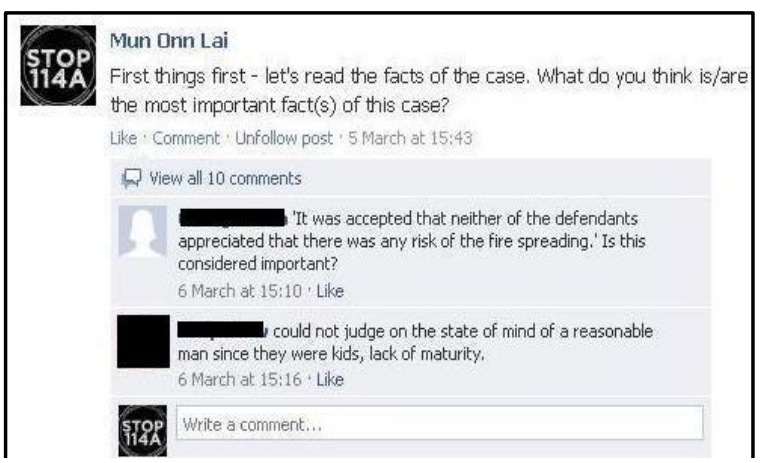

Figure 2. Discussion on Facebook

More complex questions will follow to challenge the students to think further and deeper and give their views. The discussion is facilitated by this author asking more probing questions in reply to their responses. The main objectives of this discussion were the get the students to read the case, understand the decision of the judges and critically evaluate the decision. Questions posted on the forum will have to meet these objectives. This discussion forum can last for a couple of weeks or just over a few days depending on the discussion topic.

The survey conducted after the first of these discussions revealed the following:-

- $86 \%$ of the students read all the questions posted on the FB Group page. No one indicated they did not read any questions.

- In response to the question "Did you find the questions posted in the discussion page helpful?", $36 \%$ answered "Very much", 32\% answered "Yes", 29\% answered "Somewhat" and 1 student indicated "A little bit". No one picked "Not at all" (see Table 3 below).

- When asked if they would like to have more of these kinds of discussions, all but one indicated they would like to.

\section{Table 3. Usefulness of Discussion}

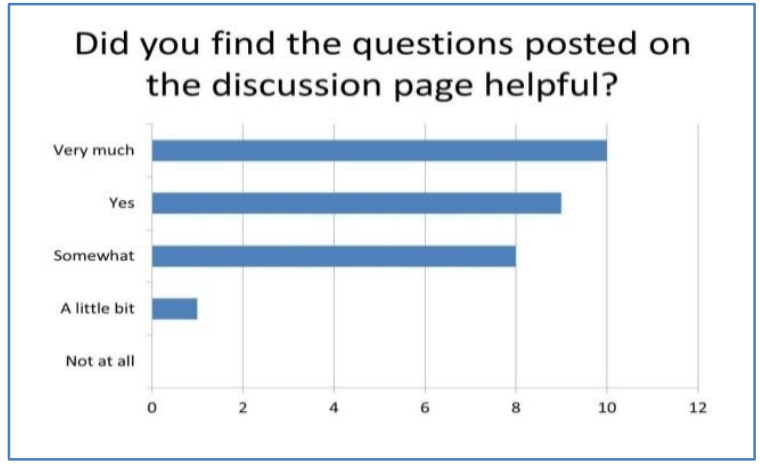

3.1.2 Reflection exercises. The same method used for Discussion forums above was adopted - a FB Group was set up to get the students to reflect over an experience they went through. Students share their thoughts and others get to comment on it too (or just "Like" it).

For example, after the students watched a movie about an abused woman who finally killed her abusing husband, they were asked to reflect about what they watched. (See Figure 3 below) 


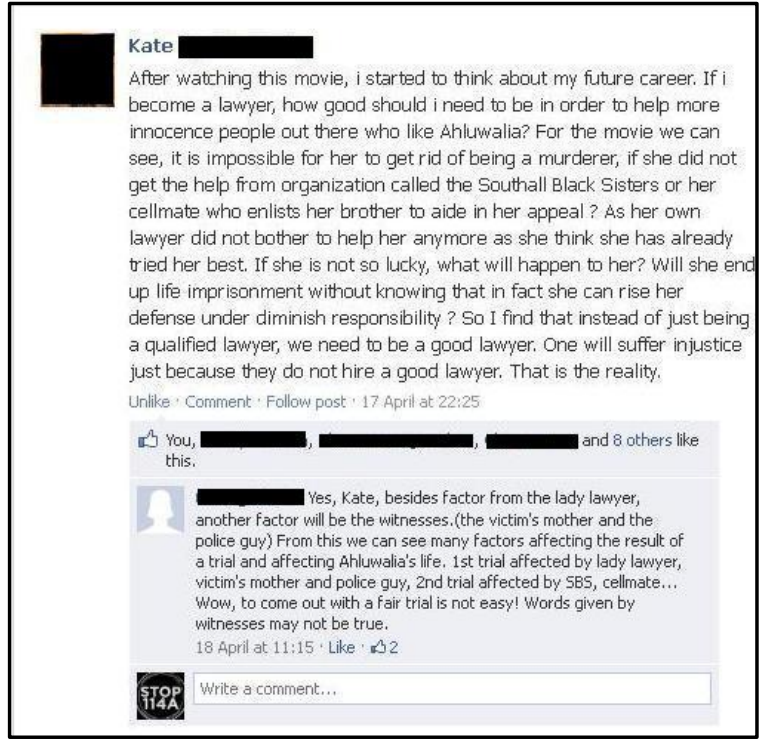

Figure 3. Reflection exercise on Facebook

The survey conducted after one of these discussions yielded the following results:-

- $94 \%$ of the students (all save for a couple) read some or all of the views expressed on the FB Group page;

- All of the students save for one expressed that they benefitted from reading the views expressed and thought that the views were either interesting and/or made them think more about the issues (see Table 4 below);

- All but 3 of them felt that a reflective exercise like that was useful.

\section{Table 4. Response to the reflection exercise}

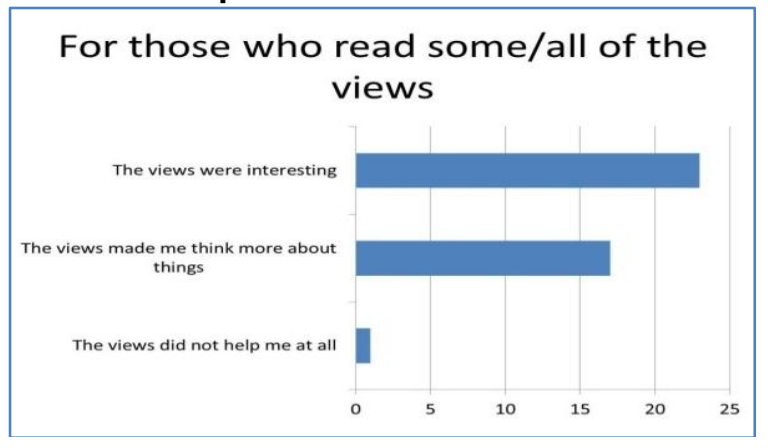

Some students found this so helpful that they asked this author to set up a FB Group to discuss and reflect over an incident which took place in the city where street protestors were injured by police personnel. Another student even set up a Discussion Group in the same manner to discuss with his classmates regarding a particular topic.

3.1.3 Quizzes. There was "Group" page set up by the students themselves where all the students were members of it. This author would put up questions on this Group page to test the students if they have done their respective readings (see Figure 4 below).

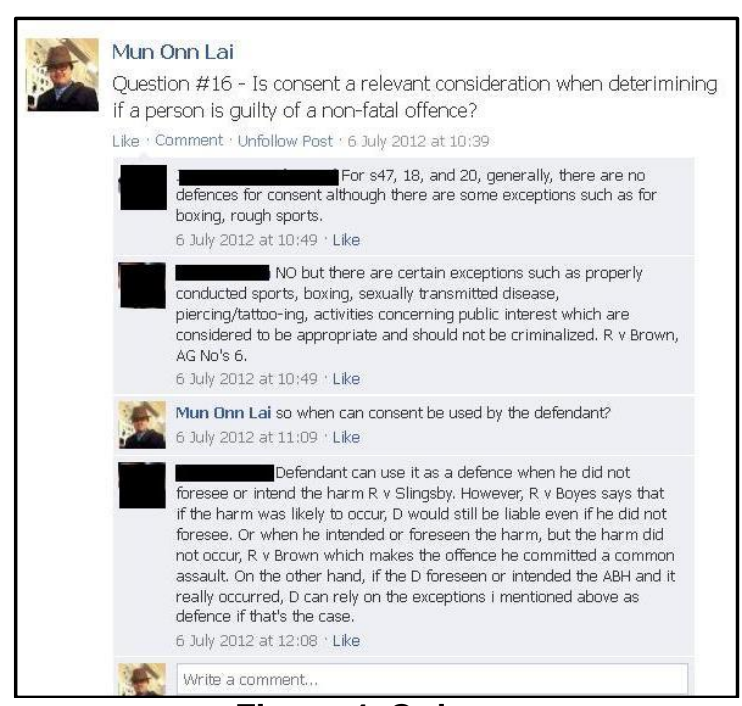

Figure 4. Quizzes

Even if certain students do not participate in the quiz, they will be notified of it and of answers being posted. In this way, they will still benefit from it.

This author had also set up a Group and named it "Revision" and added all students into that group. This group was set up a few weeks before their final exams and it was to help them revise for their exams.

Questions from each topic were posted asking them among other things, the elements needed to be proven for a specific crime and the authorities to support it. Students answered by putting their responses in the comment box. If the answers are not accurate, this author will ask further questions.

The responses were good. There were some students who took part enthusiastically and tried to answer as many questions as possible. Others just referred to it and indicate their agreement by clicking "Like" the answers ("comments").

A survey was not carried on this as this was set up and ran until the exams and after the exams, the students were all on holiday. One student informed this author (via a Facebook message of course) that he found the Revision FB Group to be useful. He said that the questions posted:-

"...turned out to be more helpful than I expected... Even though I didn't answer the questions, it helped a lot as I got to recap and think back to what I've studied previously".

3.1.4 Posting of study materials. On the FB Group pages now, it is possible to upload files there (click on "Upload file" - see Figure 5 below). Documents and PowerPoint slides have been uploaded onto the students' FB Group page - these documents are available on the official Learning Management System but students seem to prefer getting them via their Facebook page. 


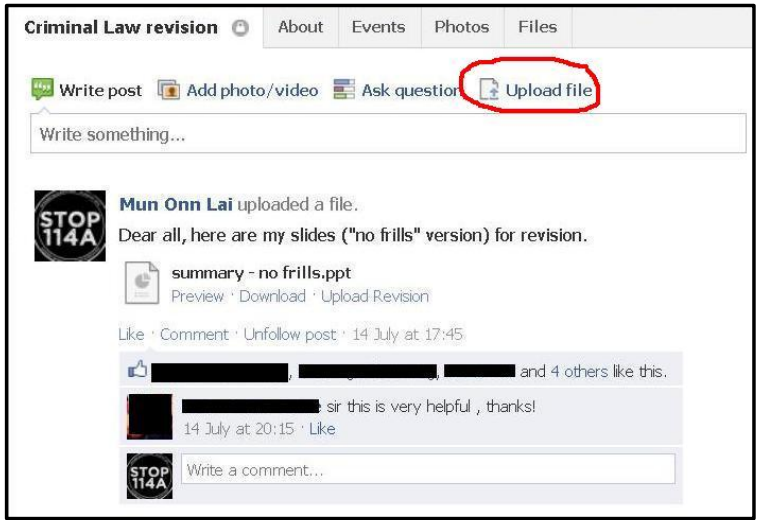

Figure 5. Posting materials on Facebook

It is also useful to link online resources as well as interesting and relevant websites and news reports on the students' class FB Group page.

3.1.5 Feedback. When a survey was conducted on the students' preferable choices on how they would like to receive feedback on their coursework, more than $84 \%$ of the responses indicated they would like to receive feedback the "traditional" way (written comments on their answer scripts) and/or in a face to face meeting. Only $12.5 \%$ of the students indicated they would not mind obtaining feedback via a message on Facebook.

Nevertheless, for their last written assignment, all feedback was given via a Facebook message. As their written work was marked, this author typed the feedback immediately onto a Facebook message box which was sent to that particular student.

Not all the students submitted the written assignment. Only 23 students responded to the survey conducted and only 1 student did not agree that receiving feedback on FB is useful.

Those who felt that receiving feedback via Facebook was useful gave the following reasons:-

- They normally check their Facebook daily;

- Quite a few felt that it was fast, easy, convenient and free. One even said it was more "environmentally friendly" (no paper is used?);

- It was just as effective as a private consultation session. Further, it is private and the student will not feel too embarrassed when mistakes are made as it is not highlighted in a face to face meeting;

- Easier to understand compared to some lecturers' handwriting!

The student who did not agree that it was useful was of the opinion that Facebook is meant only for social networking purposes.

3.1.6 Personal consultation on Facebook. Members on Facebook are able "chat" online. This gives the students the option to chat with this author on Facebook regarding anything they need to clarify. Sometimes it can be a quick question. Other times, it can be a longer discussion where this author would be needed to clarify certain things.

Some students have even posted their queries on the general class page where other students are also able to contribute their views and help each other (see Figure 6 below).

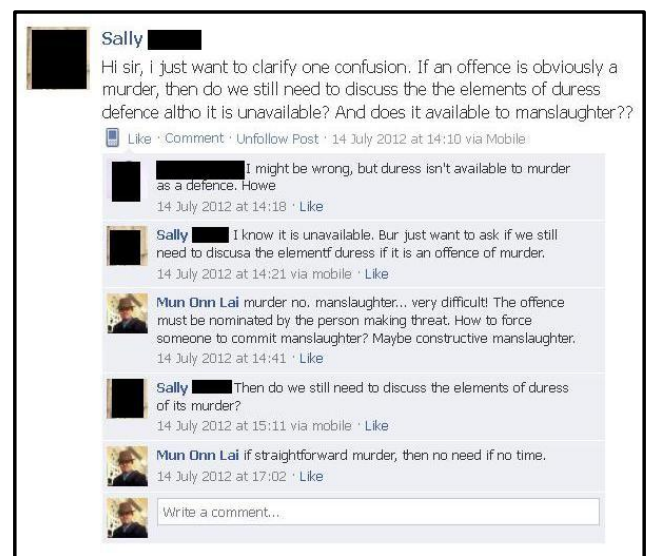

Figure 6. Students asking questions

Related to this and discussed further below under the heading of "Pastoral Care".

\subsection{Pastoral care}

This author used Facebook to carry out pastoral care by keeping in touch with his personal tutees. As they are always checking their Facebook accounts, it is convenient to "find" them there and communicate with them. This author has had online chats with his tutees to help sort out problems the students are facing be it related to studies or otherwise.

This author was required to meet his personal tutees at least once a term. They were thus given an option to "meet" him online on Facebook for a chat or to carry out the meeting through a series of Facebook messages. A survey among the personal tutees was conducted and 14 of them responded (see Table 5 below).

Table 5. Pastoral Care on Facebook

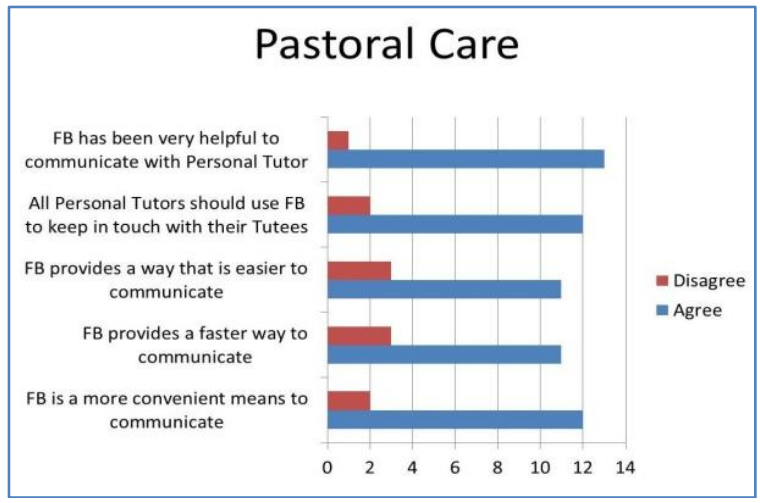

All except two agreed that all personal tutors should use Facebook to keep in touch with their tutees. They felt that using Facebook was a more convenient means to communicate. Of the two 
students who disagreed, one explained that he/she is trying to reduce time spent on Facebook. The other did not give any reasons.

An overwhelming majority felt that Facebook provided a faster and easier way to communicate with their personal tutor. Other reasons why the students agreed that Facebook should be used includes the fact that students check their Facebook often, some may not be comfortable to express their opinions and/or problems in a face to face encounter and the fact that Facebook is free!

\subsection{Administrative matters}

Finally, Facebook was used as an administration tool. This is the most basic way it can be used. Announcements can be posted up and arrangements made. Reminders of deadlines and instructions for handing up assignments can be brought to the attention of the students effectively. In fact, some of the surveys conducted and referred to in this paper were actually carried out on Facebook.

A survey regarding the use of Facebook in this manner was conducted. $65 \%$ agreed that official announcements are best made on Facebook. 23\% disagreed while the rest have no views on the matter (see Table 6 below).

Table 6. Making announcements on Facebook

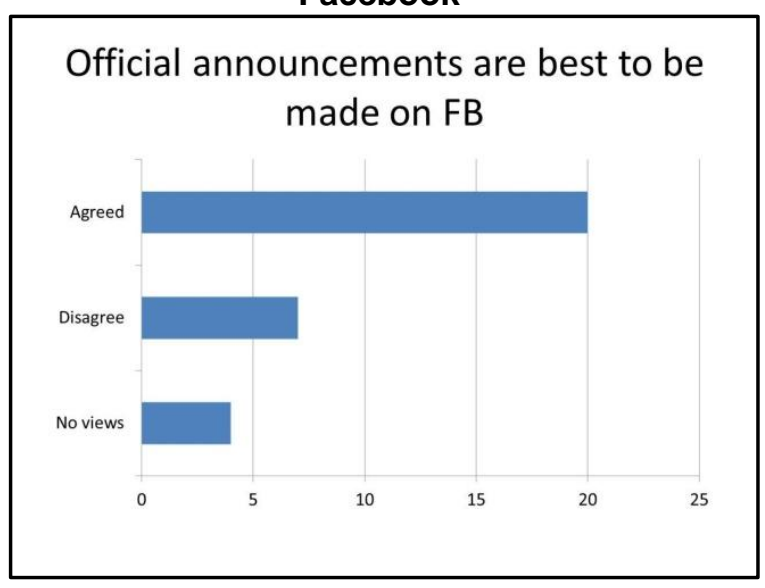

For those who indicated that they agreed, 55\% of them felt that Facebook is the best way to communicate the announcements to them while $70 \%$ of them also indicated that they check their Facebook more than they check their e-mails or Blackboard.

For those who did not agree or were indifferent, $45 \%$ of them felt that Facebook should not be used to make such important announcements while $72 \%$ of them felt that such announcements can be missed if posted on Facebook.

\section{Concluding survey}

At the end of the study, a final survey was taken to gauge how open the students were to be "friends" with their lecturers on Facebook. The survey asked 2 main questions - would they add their lecturer as a "friend" on Facebook and do they think it is a good idea to do so.

In response to the first question, 58\% said "Yes" while $42 \%$ said "Depends". No one said "no"

For those who said "Depends", 27\% said that they will add the lecturer if he/she is friendly and approachable. Another 18\% said that the lecturer must not be judgmental. Closely linked to that, $18 \%$ state that they may not be ready to share details of their personal lives with the lecturer.

In response to the second question, $73 \%$ said "Yes" while 27\% said "Maybe".

If they answered "Yes", the survey gave them 5 choices explain why they said so. The students were allowed to choose more than one answer.

The results are as follows:-

i. It makes the lecturer more approachable $-84 \%$

ii. It is easier to communicate with the lecturer $95 \%$

iii. It helps them understand the lecturer better $42 \%$

iv. It helps the lecturer understand them better $53 \%$

v. Facebook can be used to supplement lectures and tutorials $-58 \%$

Some of the students who answered "Maybe" gave reasons as to their hesitation. 29\% of those who said "Maybe" (which is basically $8 \%$ of those who took part in this survey) state that they did not want lecturers to know about their Facebook activity. They also felt that it was not professional for a lecturer to relate to a student in that way and that it is "weird".

\section{The views of lecturers}

Finally, this author conducted a survey among his colleagues in the Law School. It is important to note that the Law School was a very small school and there were only 7 lecturers who took part in the survey.

Out of the 7 lecturers, 3 of them do not have a Facebook account. Out of these 3 lecturers, two said they would not sign up for an account even if Facebook could be used to supplement their teaching. The third lecturer was willing to sign up for a Facebook account.

Of the 4 lecturers who have a Facebook account, half of them are on Facebook for less than 2 hours a day. None of them have ever used Facebook in any way as a teaching tool. Two of them said that they did not know how. One said that he/she has not had the opportunity to do so.

The final lecturer was of the view that using Facebook as a teaching tool was not appropriate. 
This lecturer did not want to add students as "Friends" on Facebook as it is his/her personal space. This lecturer was also of the view that students may be disadvantaged if Facebook was used as some of them (in the view of this lecturer) do not have a Facebook account and/or good internet connection.

Having said that, all 4 lecturers (who have a Facebook account) said that they were willing to try to use Facebook as a teaching tool.

\section{Findings and views}

This project was conducted for the entire academic year, and at end of it, here are some of the findings made by this author.

\subsection{Having a Facebook account}

It was very important that all the students have a Facebook account. The fact that all students have an account made it easier and fairer to use Facebook to supplement the classroom teaching. As such, the concern of my colleague that students will be disadvantaged if they do not have an account is academic.

Even if students do not have a Facebook account, it is submitted that it is not a big problem as it is indeed very easy for a student to sign up for an account. Facebook is free and readily available to anyone who is able to go online.

Furthermore, as found in the preliminary survey, most students find that using Facebook is easy none of them have any difficulty using Facebook. It is pertinent to note that this study was conducted among law students. While law students may not have a good knowledge and understanding of technology and/or computers as compared to students of the science stream, Facebook is simple enough to be used expertly by them. There is therefore no need for students to be trained how to use Facebook.

Universities these have their own Learning Management System ("LMS") which can be quite challenging for some students as it can get very complicated to use. Trainings are usually held for both students and staff but it is submitted that one can only really learn to use the LMS well if one learns by actually using it. For those who do not know how - or are "technologically-challenged" will find it difficult and may even give up using it.

This study shows that Facebook, while not as versatile as a LMS, is nevertheless very simple to use. In fact, the students are already using it.

Having a Facebook account seems to be a big problem when it comes to the lecturers. It is found that almost half of the lecturers who took part in the final survey do not have a Facebook account. What was alarming was the fact that most of them do not want to sign up for an account even if Facebook could be used to supplement their teaching.

Having said that, it was encouraging to note that the lecturers who do in fact have a Facebook account are willing to try to use Facebook as an education tool. This also shows the need of training in this area.

Closely related to the issue of students having a Facebook account is the need for good internet connection. This study was conducted in a fairly modern town and the University has free Wi-Fi all over the campus. As such, this issue was not a problem in this study.

It is conceded that this can be a real problem when dealing with poorer students living in rural areas and who do not have computers let alone an internet connection.

\subsection{Acceptance}

The main problem in this author's view is the question of acceptance. The students will have to be willing to use their Facebook account in this manner and the University must be willing to allow the lecturers to use Facebook.

A small minority of students are of the view that Facebook should not be used at all for educational purposes. It is a social networking site and for some, this is the place they go to escape from their studies albeit on a temporary basis. They do not want to receive messages regarding their failures or mistakes they made in their recent assignments not get instructions to take some quiz or do a survey.

This problem can be easily overcome by the student just choosing not to refer to messages from their lecturers and notifications regarding the FB groups related to their studies. In any event, most of their friends on Facebook are their classmates and/or coursemates - and realistically, Facebook can never be a place where they are free from any mention or discussion regarding their studies. In fact, it was the students themselves who first set up their class FB group so that they can check with each other regarding classes and changes of lectures and deadlines and assignments.

As for the lecturers, the difficulty will be getting the more experienced lecturers to accept Facebook as an education tool. Many will want to stick to their old methods of teaching which has been useful and successful in their experience. These lecturers do not see the need to learn new ways to supplement their teaching. Perhaps they think that either there is no need to supplement the teaching in the classroom or that supplementing the classroom teaching should be done in other ways.

The saying is that you can't teach an old dog new tricks. It is submitted that while it may be difficult, it surely is not impossible. Lecturers will have to realise that educators need to move along with the times and they will have to learn to accept 
and adopt the new technology that is available. What may work well in the past need not necessarily be successful today. While the subject matter may not change much, students today are not the same as students in the past.

It is submitted that the lecturers should meet the needs of the students and approach teaching in a way that appeals to them and in a way that is relevant. Technology is not exclusively used in education. Students who graduate today will be expected to know how to use technology. They will have to start to learn how to master it while they are students.

As for the University, it may be hard to get them to agree to use Facebook in this manner. The culture here in Malaysia is that Facebook is not taken too seriously in terms of education. Furthermore, the University has invested in a LMS where everything that was conducted in this project (discussion groups, quizzes, etc.) can be done. The University may not be so keen to adopt Facebook when we have the LMS.

While it is true that what has been carried out in this project can be done using the University's LMS, it is submitted that the effectiveness may not be the same. As mentioned by this author's students in their survey responses, the things that were carried out worked mainly because the students are on Facebook most of the time and they are familiar and comfortable using it. It is not the same when it comes to the University's LMS.

\subsection{Privacy}

Some students have informed this author that they would like their privacy on Facebook to be respected. As such, they would not want to add this author as a "friend" on Facebook as they would like to carry on their activities on Facebook without fear of lecturers knowing or intruding into their private space.

In the concluding survey, it is no surprise to find that some students will only consider adding lecturers as their "friends" on Facebook if the lecturers are not in their view, judgmental.

Some of the students who do not think that adding their lecturers as "friends" on Facebook is a good idea as they do not want the lecturers to know about their Facebook activity.

This problem can however be easily overcome. For example, there was this particular student who until today has not added this author as a "friend" on Facebook. However, she has taken part in this project as the other students added her into the class Facebook page as well as added her in to the discussion FB groups that I had set up. Further, this author was still able to send and receive Facebook messages from this student and as such, this author was able to keep in contact with this student and give her feedback and advice through Facebook messages.

Facebook have also functions which limits what activities of yours that your friends can see. It is therefore possible for a student to add a lecturer as a "friend" on Facebook and list the lecturer as "Restricted". The student can control what the lecturer can see of his activities on Facebook and thus his privacy on Facebook is assured.

Similarly, it is found that this was also the concern by one of the lecturers where he/she felt that his/her Facebook account is his personal and private space. This can be easily overcome by adjusting the privacy settings.

Alternatively, the lecturer can do what this author did - this author set up another Facebook account solely and exclusively to use among his students.

It may be too cumbersome on the students to expect them to set up a new account just to use for education purposes (and it may end up being underutilised and ineffective like the University's LMS), but if a lecturer is serious about using Facebook to supplement the classroom teaching, opening up another account is not too troublesome - and speaking from experience, very much worth the effort.

\subsection{Facebook is popular amongst students}

This project has been made easy by the fact that Facebook is extremely popular amongst the students today. As seen in the preliminary survey (see Table 1 above), the students are on Facebook most of the time. Some are even on Facebook all the time, being connected by their mobile devices. This only shows that the students enjoy using Facebook. They are logged on in their Facebook account because they like interacting with their friends in that way.

By taking some of the lessons out of the classroom and placing it in a place where they are always at and comfortable with, this author found that the students participated with more enthusiasm and willingness. For example, a discussion board placed on the LMS may not have received so much participation as compared with having it on Facebook. The students are already logged on to their Facebook accounts but as the preliminary survey showed, not many of them even log on to their account on Blackboard which is the LMS used in this University.

The willingness and enthusiasm is demonstrated also in the responses of the students to the discussion boards and reflection exercises carried out on Facebook (see Tables 3 and 4 above). The students mainly found it useful and indicated they would like to have more of it. As mentioned above, some students have requested for more of such discussion 
on Facebook while a student even started his own discussion group.

While it is immensely popular amongst the students, the same cannot be said of the lecturers. Only 4 out of 7 lecturers have a Facebook account and half of them are on Facebook less than 2 hours a day.

It is submitted that once lecturers have a change of mind-set and realise the potential of using Facebook, they will use it for teaching purposes even if they do not use it much for their own personal needs.

\subsection{Facebook can improve lecturer-student relationship}

This author found that Facebook can be effectively used to keep in touch with his students. My personal tutees were also of the view that using Facebook was helpful to communicate with me (see Table 5 above). Some of the, even went so far to say that all lecturers should use Facebook to communicate with their tutees. The reason why communication was better on Facebook was revealed in the concluding survey.

In the concluding survey, as seen above, a big percentage of students were of the view that being "friends" with their lecturer on Facebook is a good idea because it makes the lecturer more approachable and therefore it was easier to communicate with their lecturer.

This should not be a surprise. By using Facebook to communicate with the students, a lecturer is basically going on to a platform where students are comfortable in. Instead of expecting the students to come to their level, the lecturers go to the students and this can show that they are approachable.

It is submitted that an improved relationship will help in the education of the students, both inside and outside of classroom. Students will be more willing and motivated to participate in the discussion forums and other groups on Facebook set up by a lecturer that they have a good relationship with. There is less apprehension of being judged by the lecturer and more openness in communication. Students will be more willing to discuss with their lecturers about their studies and raise questions and queries on matters which they are struggling with.

\section{Conclusion}

Based on the results of the project and the responses obtained from the students involved in the project, Facebook can be used as an educational tool. It is free and freely available and students are already using Facebook. Therefore it is a convenient and fast way to communicate and interact with the students.
While there may be some resistance to the idea of using a social networking site for educational purposes, these resistance must be countered with the fact that there is a time when education must be brought to the students where they are. Students are on Facebook and they are open to the idea of using Facebook as a tool. The benefits of using Facebook shall therefore surely outweigh any fears and concerns that may be felt, rightly or otherwise.

In the $21^{\text {st }}$ century, the use of technology is indeed being more prominent in education. The end that we seek is not what technology can teach us, but how using it can help us in education. Using technology is no longer an activity we engage in but a space that we and our students occupy and live in [4].

It must also be borne in mind that this paper proposes the use of Facebook (or any social networking site) as a tool for education, not the means. Facebook with its advantages as pointed out in this paper can surely be used to supplement and aid in the education process of today's students who are familiar with its use and are constantly using it.

While there has been calls for more studies made to see if the benefit of using Social Networking Sites like Facebook as a tool to complement the education of today's students is worth the cost of retooling and restructuring the present style and syllabus used today [7], it is submitted that the syllabus need not be changed but the manner of how it is delivered can be improved and supplemented with the use of Facebook today.

\section{References}

[1] Boyd, D.M. \& Ellison, N.B. (2007). Social Network Sites: Definition, History and Scholarship. Journal of Computer-Mediated Communication, 13(1), Article 11.

[2] Cresswell, J.W. Educational Research - Planning, Conducting, and Evaluating Quantitative and Qualitative Research $\left(2^{\text {nd }} E d\right)$ Pearson Education Ltd 2005

[3] Ellison, N. B., Steinfield, C., \& Lampe, C. (2007). The benefits of Facebook "friends:" Social capital and college students' use of online social network sites. Journal of Computer-Mediated Communication, 12(4), article 1.

[4] Gerben, Chris. (2009). Putting 2.0 and Two Together: What Web 2.0 Can Teach Composition About Collaborative Learning. Computers and Composition Online Fall 2009.

[5] Key Facts, Facebook.

[6] Madge, C., Meek, J., Wellens, J. \& Hooley, T. (2009). Facebook, social integration and informal learning at university: 'It is more for socialising and talking to friends about work than for actually doing work'. Learning, Media and Technology, 2009, 34 (2), pp. 141-155. 
[7] Munoz, C. \& Towner, T. (2009). Opening Facebook: How to Use Facebook in the College Classroom. In I. Gibson et al. (Eds.), Proceedings of Society for Information Technology \& Teacher Education International Conference 2009 (pp. 2623-2627). Chesapeake, VA: AACE.

[8] Stella Wen Tian, Angela Yan Yu, Douglas Vogel, Ron Chi-Wai Kwok. The impact of online social networking on learning: a social integration perspective. International Journal of Networking and Virtual Organisations, 2011; 8 (3/4): 264-280 DOI: 10.1504/IJNVO.2011.039999

[9] University of Minnesota (2008, June 21). Educational Benefits Of Social Networking Sites Uncovered. ScienceDaily.

\section{Acknowledgements}

The author wishes to thank Cheah Su Ming for reading through the first draft and giving valuable comments and suggestions. 